\title{
Endothelial interactions of neutrophils under flow in chronic obstructive pulmonary
} disease

\author{
I.S. Woolhouse*, D.L. Bayley*, P. Lalor ${ }^{\#}$, D.H. Adams ${ }^{\#}$ and R.A. Stockley*
}

ABSTRACT: It is generally accepted that the neutrophil is central to the pathogenesis of chronic obstructive pulmonary disease (COPD). Enhanced endothelial interactions of this cell may contribute to the susceptibility of smokers who develop the disease; however, these interactions have not previously been studied in COPD. The aim of the current study was to determine whether enhanced endothelial interactions of neutrophils from smokers are a predisposing factor for the development of COPD.

Endothelial interactions under flow and adhesion molecule expression of peripheral blood neutrophils were compared between seven never-smokers (NS), seven healthy smokers (HS), 11 COPD patients with severe $\alpha_{1}$-antitrypsin deficiency (PiZ) and neutrophils from 11 COPD patients without the deficiency (PiM).

Total adhesive and migratory responses (per $\mathrm{mm}^{2}$ endothelium per $10^{6}$ neutrophils) were significantly greater in the PiM group (mean \pm SE $704.2 \pm 57.9$ versus $509.3 \pm 48.8$ in the PiZ group, $499.3 \pm 40.1$ in the HS and $491.2 \pm 33.7$ in the NS). This corresponded with increased macrophage antigen-1 (CD11b) expression on stimulated neutrophils in the PiM group compared with the PiZ group (mean \pm SE relative fluorescence intensity $1.4 \pm 0.1$ versus $1.1 \pm 0.1$ ).

In conclusion, the enhanced endothelial interaction of neutrophils from smokers who have developed chronic obstructive pulmonary disease in the presence of normal levels of $\alpha_{1}$ antitrypsin deficiency, but not in those with severe $\alpha_{1}$-antitrypsin deficiency, suggests that this is a predisposing factor for the development of the disease, and upregulation of macrophage antigen1 may be responsible.

KEYWORDS: $\alpha_{1}$-Antitrypsin, cell-adhesion molecules, chronic obstructive pulmonary disease, endothelium, neutrophils

I $\mathrm{t}$ is generally accepted that the neutrophil is central to the pathogenesis of chronic obstructive pulmonary disease (COPD) $[1,2]$. Enhanced endothelial interactions of this cell may contribute to the susceptibility of smokers who develop the disease, via increased recruitment from the bloodstream into the lungs. Neutrophil migration into the bronchial submucosa occurs via the bronchial circulation, and it is assumed to follow the multistep process of selectin-mediated cell rolling and capture, followed by $\beta_{2}$-integrin (CD18)-mediated adhesion and then transmigration [3]. There is now evidence that the recruitment of activated neutrophils can involve other, novel molecular pathways. For example, in acute sepsis, neutrophils have been shown to use $\alpha_{4}$-integrins (CD49d), as well as $\beta_{2}$-integrins to interact with endothelium [4], and other workers have implicated leukosialin (CD43) in the neutrophil locomotor and migratory responses [5]. However, these adhesion molecules have not previously been assessed in chronic inflammatory diseases, such as COPD.

A previous study of conventional neutrophil adhesion molecules in COPD demonstrated increased expression of macrophage antigen (Mac)-1 (CD11b) in smokers with airflow obstruction compared to smokers with normal lung function [6]. In addition, enhanced chemotactic response of neutrophils from patients with chronic bronchitis and emphysema has been previously demonstrated, using the membrane filter method with the bacterial peptide formylmethionyl-leucyl-phenylalanine (fMLP) as the chemoattractant [7]. However, it is not known whether this upregulation of Mac-1 and enhanced chemotactic response across an inert membrane translates into increased neutrophilendothelial interactions in smokers who have

\section{AFFLLIATIONS}

*Dept of Respiratory Medicine, and \#Liver Research Laboratory, University Hospital Birmingham, Birmingham, UK.

CORRESPONDENCE

I.S. Woolhouse

Dept of Respiratory Medicine University Hospital Birmingham Birmingham B29 6JD UK

Fax: 441216272012

E-mail: lan.Woolhouse@uhb.nhs.uk

Received:

July 222004

Accepted after revision:

December 072004

SUPPORT STATEMENT

I.S. Woolhouse was funded by a Boehringer clinical fellowship (Ingelheim, Germany). The patients with antitrypsin deficiency were recruited from the Antitrypsin Deficiency, Assessment and Programme for Treatment (ADAPT), funded by a noncommercial scientific grant by Bayer plc (Leverkusen,

Germany). R.A. Stockley is a member of the Alpha 1 International Registry. 
developed COPD. Furthermore, it is not clear whether the neutrophil priming described to date is a predisposing factor for COPD or a consequence of the disease.

Therefore, the aims of the current study were to test the hypotheses that neutrophils purified from the blood of COPD patients with normal levels of $\alpha_{1}$-antitrypsin (AT) demonstrate: 1) enhanced endothelial interactions under flow conditions, and 2) adhesion molecule upregulation compared with neversmokers (NS), healthy smokers (HS) and COPD patients with a recognised genetic predisposition for the disease (i.e. severe $\alpha_{1}$ AT deficiency).

\section{METHODS}

\section{Study populations}

Blood samples were collected on a single occasion from seven NS, seven HS, 11 COPD patients with normal $\alpha_{1}$-AT (PiM) and 11 COPD patients with $\alpha_{1}$-AT deficiency (PiZ), at least 2 months after any acute exacerbation. COPD was defined as a forced expiratory volume in one second (FEV1)/forced vital capacity (FVC) ratio of $<70 \%$ [8].

\section{Endothelial cell isolation and culture}

Human umbilical vein endothelial cells (HUVEC) were harvested from umbilical cords, using a previously described technique [9]. The HUVEC were grown in Human EndothelialSFM Basal Growth Medium (Invitrogen Corp., Paisley, UK) supplemented with $10 \%(\mathrm{v} / \mathrm{v})$ heat-inactivated human blood group $\mathrm{AB}$ serum (HD supplies, Buckinghamshire, UK), $10 \mathrm{ng} \cdot \mathrm{mL}^{-1}$ Epidermal Growth Factor (Peprotech EC Ltd, London, UK), $10 \mu \mathrm{g} \cdot \mathrm{mL}^{-1}$ hydrocortisone, $0.06 \mathrm{mg} \cdot \mathrm{mL}^{-1}$ penicillin, $0.1 \mathrm{mg} \cdot \mathrm{mL}^{-1}$ streptomycin (all hospital pharmacy preparations), and $10 \mu \mathrm{g} \cdot \mathrm{mL}^{-1}$ glutamine (Sigma Chemicals Ltd, Poole, UK), at $37^{\circ} \mathrm{C}$ in a humidified atmosphere containing $5 \%$ $\mathrm{CO}_{2}$. Cells were subcultured to confluence and the growth cycle repeated as required. Cells were not used beyond their sixth passage. HUVEC were chosen for this study because of the ease of culture to confluence within the glass microslide, and the similar profile of adhesion molecule expression following interleukin (IL)-1 $\beta$ stimulation to that seen on postcapillary venules in the bronchial circulation of smokers $[10,11]$.

\section{Isolation of blood neutrophils}

Whole blood was collected by venepuncture into tubes containing EDTA anticoagulant, and neutrophils were isolated using discontinuous density-gradient centrifugation on Histopaque ${ }^{\circledR} 1019$ and 1077 (Sigma Chemicals Ltd) at $500 \times g$ for $25 \mathrm{~min}$. All stages were performed at room temperature. Contaminating red blood cells were removed by ammonium chloride lysis buffer $\left(1.66 \mathrm{~g} \mathrm{NH}_{4} \mathrm{Cl}, 200 \mathrm{mg} \mathrm{KHCO}_{3}\right.$ and $7.4 \mathrm{mg}$ disodium EDTA (BDH, Poole, UK) in $200 \mathrm{~mL}$ distilled water, adjusted to $\mathrm{pH}$ 7.2). Cells were washed with PBS containing $0.1 \%$ bovine serum albumin (Sigma Chemicals Ltd) prior to use. This method produced neutrophils that were $98 \%$ pure and $97 \%$ viable (as determined by trypan blue exclusion).

\section{Flow-based adhesion and migration assay}

A flow-based assay was used as described previously [12]. Glass microslides with a rectangular cross-section and good optical qualities (Camlab Ltd, Cambridge, UK), coated with 3-aminopropyltriethoxy-silane (Sigma Chemicals Ltd) and gelatin solution, were seeded with HUVEC at a concentration of $1.5 \times 10^{6} \cdot \mathrm{mL}^{-1}$ to give spreading and confluence. HUVEC were stimulated with IL-1 $\beta\left(10 \mathrm{ng} \cdot \mathrm{mL}^{-1}\right)$ for $4 \mathrm{~h}$ prior to each assay. The endothelialised microslides were then mounted on the stage of a phase-contrast light video microscope (enclosed in a heated transparent acrylic chamber at $37^{\circ} \mathrm{C}$ ) and connected to a Harvard syringe pump (Harvard Apparatus, Holliston, MA, USA) to allow buffer or cell suspension to be drawn across the HUVEC monolayers by means of an electronic switching valve (Lee Products Ltd, Buckinghamshire, UK).

A bolus of density-fractionated neutrophils $\left(1 \times 10^{6} \cdot \mathrm{mL}^{-1}\right.$ in endothelial basal growth medium with $0.1 \%$ bovine serum albumin) was perfused through the microslide for $4 \mathrm{~min}$, followed by a washout with cell-free endothelial basal growth medium for $90 \mathrm{~s}$. The flow rate was set at $0.182 \mathrm{~mL} \cdot \mathrm{min}^{-1}$, producing a wall shear stress of $0.05 \mathrm{~Pa}$. This is at the lower end of the range typically found in post-capillary venules [13]. Video recordings were made over the next $60 \mathrm{~s}$, covering at least 10 fields of the microslide. These recordings were subsequently analysed by counting the number of adherent (phase bright) and transmigrated leukocytes (phase dark) per field. The number of adherent and migrated neutrophils $\cdot \mathrm{mm}^{-2} \cdot 10^{6}$ cells $^{-1}$ infused could then be determined. The intra-assay coefficient of variation $(n=6)$ was $3.1 \%$ for adherent neutrophils, $10.1 \%$ for migrated neutrophils and 3.5\% for total interacting neutrophils. Endothelial adhesion and migration experiments were performed in triplicate, and the average was obtained and taken as the result for each study subject.

\section{Neutrophil surface-adhesion molecule expression}

Fluorescein isothiocyanate isomer-conjugated monoclonal antibodies directed against CD11a, CD18 (Dako, Ely, UK), CD11b, CD43, CD49d, CD62L, immunoglobulin (Ig)G1 and IgG2b (Serotec, Oxford, UK) were used to label surface-adhesion molecules on resting and fMLP-stimulated neutrophils purified from the whole blood of each study subject, as described previously [14]. Briefly, $50 \mu \mathrm{L}$ of the neutrophil suspension was added to either $50 \mu \mathrm{L}$ PBS or $50 \mu \mathrm{L}$ of $1-\mu \mathrm{M}$ fMLP and incubated for $15 \mathrm{~min}$ at room temperature. After incubation with the appropriate monoclonal antibody for $30 \mathrm{~min}$ at room temperature, protected from the light, the cells were washed twice with $1.5 \mathrm{~mL}$ of wash buffer (500 mL PBS, $0.1 \mathrm{~g}$ sodium azide (Sigma Chemicals Ltd) and $2 \% \mathrm{v} / \mathrm{v}$ foetal calf serum). Following the second wash, the cell pellet was resuspended in $500 \mu \mathrm{L}$ of $1 \%(\mathrm{w} / \mathrm{v})$ paraformaldehyde (Sigma Chemicals Ltd), and the samples were then stored at $4{ }^{\circ} \mathrm{C}$, protected from light until analysed. Cell-surface fluorescence was assessed using a Coulter Epics XL machine (Coulter Corp., Miami, FL, USA). The intensity of fluorescence for unstimulated neutrophils labelled with specific antibody was determined relative to the intensity of fluorescence for cells labelled with nonspecific antibody. The intensity of fluorescence of fMLP-treated cells was expressed relative to unstimulated neutrophils labelled with the same antibody. The intra-assay coefficient of variation $(n=4)$ for this method was $9.3 \%$.

\section{Haematological measurements}

An automated full blood count was performed on each study subject using the Abbott Cell Dyn 4000 analyser (Abbott 
Laboratories, Milton Keynes, UK) in the Haematology Dept of the Queen Elizabeth Hospital, Birmingham, UK.

\section{Statistical analysis}

Continuous data for the four groups were initially compared using the Kruskal-Wallis test, followed by the Mann-Whitney U-test to identify significant differences between pairs of groups. Categorical data were compared using a Chi-squared test. The Spearman's rank correlation test was used to examine the relationship between variables. A p-value $<0.05$ was considered to be statistically significant. This study was approved by the South Birmingham Health Authority Ethics Committee, Birmingham, UK, and all subjects provided written informed consent.

\section{RESULTS}

\section{Study subjects}

Demographic and spirometric data for the NS, HS, PiM and $\mathrm{PiZ}$ groups are shown in table 1. The PiZ group was significantly $(\mathrm{p}<0.01)$ younger than the other three groups, but the sex differences between groups were not statistically significant $(p=0.317)$. The HS, PiM and PiZ groups had a similar pack-yr smoking history, and there were no differences between current and ex-smokers $(p=0.353)$. The PiM and PiZ groups had a similar average degree of airflow obstruction, i.e. moderate to severe.

\section{Haematological parameters}

The results of automated full blood count testing are shown in table 2. The mean white blood cell and neutrophil counts were similar in the HS, PiM and PiZ groups, but significantly lower $(\mathrm{p}<0.01)$ in the NS group. The mean haemoglobin concentration and haematocrit was significantly higher $(p<0.05)$ in the PiM and PiZ groups compared with the NS and HS groups.

\section{Neutrophil adhesive and migratory behaviour under flow}

The adhesive and migratory response of neutrophils purified from the NS, HS, PiM and PiZ groups are summarised in figure 1. The mean number of adherent neutrophils was not significantly different between the four groups (Kruskal-Wallis $p=0.114)$; however, there were significant differences in the mean numbers of migrated and total interacting neutrophils

\begin{tabular}{lcccc} 
TABLE 1 & $\begin{array}{l}\text { Demographic and spirometric characteristics of } \\
\text { the study subjects }\end{array}$ \\
& NS & HS & PiM & PiZ \\
\hline & $61.4 \pm 12.3$ & $63.3 \pm 5.9$ & $69.4 \pm 7.4$ & $55.0 \pm 7.6^{* *}$ \\
Age & $2 / 5$ & $4 / 3$ & $6 / 5$ & $9 / 2$ \\
Male/female & & $5 / 2$ & $5 / 6$ & $2 / 9$ \\
Current/ex-smokers & $0 \pm 0$ & $34.1 \pm 13.3$ & $43.9 \pm 17.1$ & $25.0 \pm 22.1$ \\
Pack-yrs & $103.0 \pm 11.2$ & $95.9 \pm 13.8$ & $35.5 \pm 7.9$ & $36.1 \pm 16.1$ \\
FEV $\mathbf{1} \%$ pred & $75.4 \pm 3.5$ & $74.1 \pm 2.3$ & $38.5 \pm 9.8$ & $35.0 \pm 14.3$ \\
\hline FEV $\mathbf{1}$ FVC \% & & & & \\
\hline
\end{tabular}

Data are presented as mean \pm SD and $n$. NS: never-smokers; HS: healthy smokers; PiM: chronic obstructive pulmonary disease (COPD) patients with normal $\alpha_{1}$-antitrypsin (AT); PiZ: COPD patients with $\alpha_{1}$-AT deficiency; FEV1: forced expiratory volume in one second; \% pred: \% predicted; FVC: forced vital capacity. ${ }^{* *}: \mathrm{p}<0.01$ versus NS, HS and PiM.
TABLE 2 Haematological parameters in whole blood

\begin{tabular}{|c|c|c|c|c|c|}
\hline & NS & HS & PiM & PiZ & $p$-value \\
\hline$W B C \times 10^{9} \cdot L^{-1}$ & $5.8 \pm 0.7^{\#}$ & $8.5 \pm 2.7$ & $8.0 \pm 1.3$ & $7.8 \pm 1.4$ & 0.006 \\
\hline Neutrophils $\times 10^{9} \cdot \mathrm{L}^{-1}$ & $3.1 \pm 0.7^{\#}$ & $5.1 \pm 2.1$ & $5.1 \pm 1.2^{\#}$ & $4.8 \pm 1.1$ & 0.009 \\
\hline Lymphocytes $\times 10^{9} \cdot \mathrm{L}^{-1}$ & $2.0 \pm 0.4$ & $2.5 \pm 0.6$ & $2.0 \pm 0.8$ & $2.1 \pm 0.6$ & 0.275 \\
\hline $\mathrm{Hb} \mathbf{g} \cdot \mathrm{dL}^{-1}$ & $14.4 \pm 0.8$ & $14.9 \pm 1.0$ & $15.7 \pm 1.2^{\bullet}$ & $15.9 \pm 1.2$ & 0.033 \\
\hline Het $L \cdot L^{-1}$ & $0.44 \pm 0.03$ & $0.45 \pm 0.03$ & $0.48 \pm 0.04^{\circ}$ & $0.49 \pm 0.03^{\circ}$ & 0.019 \\
\hline Platelets $\times 10^{9} \cdot \mathrm{L}^{-1}$ & $274 \pm 53$ & $291 \pm 74$ & $297 \pm 65$ & $295 \pm 63$ & 0.858 \\
\hline
\end{tabular}

Data are presented as mean $\pm \mathrm{SD}$, unless otherwise stated. NS: never-smokers: HS: healthy smokers; PiM: chronic obstructive pulmonary disease (COPD) patients with normal $\alpha_{1}$-antitrypsin (AT); PiZ: COPD patients with $\alpha_{1}$-AT deficiency; WBC: white blood cell, Hb: haemoglobin; Hct: haematocrit. \#: $\mathrm{p}<0.05$ versus $\mathrm{HS}$, PiM and $\mathrm{PiZ} ;{ }^{\circ}: \mathrm{p}<0.05$ versus NS and HS.

between the four groups (Kruskall-Wallis $\mathrm{p}<0.01$ and $\mathrm{p}<0.05$, respectively).

Paired analysis revealed that neutrophils from the PiM group demonstrated significantly higher levels of total endothelial interaction compared with the other three groups (mean $\pm \mathrm{SE}$ $704.2 \pm 57.9$ versus $509.3 \pm 48.8, \mathrm{p}=0.01$, in the PiZ group; $499.3 \pm 40.1, \mathrm{p}<0.05$, in the HS; and 491.2 $\pm 33.7, \mathrm{p}<0.01$, in the NS), and significantly greater transendothelial migration $(327.8 \pm 36.5$ versus $86.8 \pm 24.0, \mathrm{p}<0.001$, in the PiZ group; $204.0 \pm 37.1, \mathrm{p}<0.05$, in the HS; and 204.7 $\pm 38.5, \mathrm{p}<0.05$, in the NS). In addition, transendothelial migration in the PiZ group was significantly lower than the other three groups $(p<0.05)$.

In the PiM group, a moderately strong inverse correlation was seen between total neutrophil-endothelial interactions and FEV1/FVC ( $\mathrm{r}=-0.716 ; \mathrm{p}=0.012$; fig. $2 \mathrm{a})$, but not with FEV1 expressed as $\%$ pred $(r=-0.273 ; p=0.416$; fig. $2 b)$. The correlation coefficient between total neutrophil-endothelial interactions and FEV1/FVC remained statistically significant, even

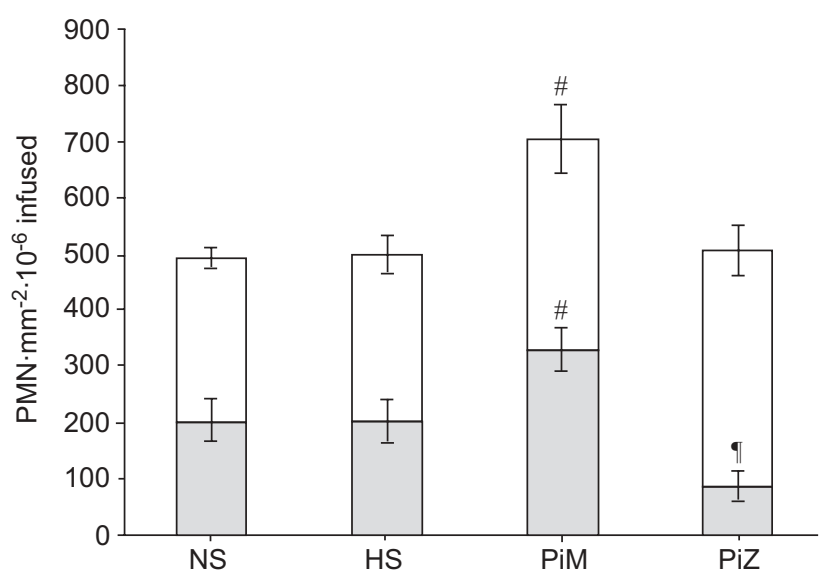

FIGURE 1. The adhesive $(\square)$ and migratory ( $\square$ ) response of neutrophils from never-smokers (NS), healthy smokers (HS), chronic obstructive pulmonary disease (COPD) patients with normal $\alpha_{1}$-antitrypsin (AT) levels (PiM) and COPD patients with $\alpha_{1}$-AT deficiency (PiZ). Data are presented as mean \pm SE. ${ }^{\#}: p<0.05$ for total interacting and migrated neutrophils versus NS, HS and PiZ; ${ }^{\circ}: p=0.05$ for migrated neutrophils versus NS, HS and PiM. 


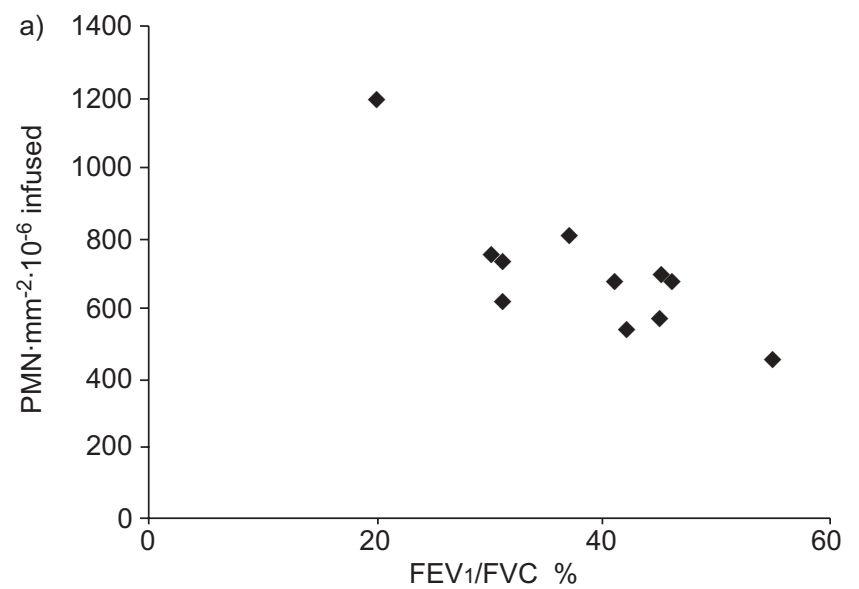

b)

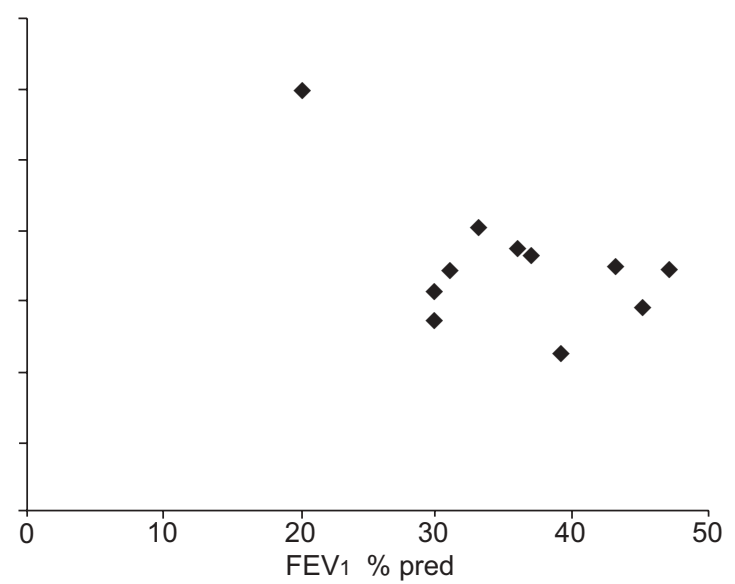

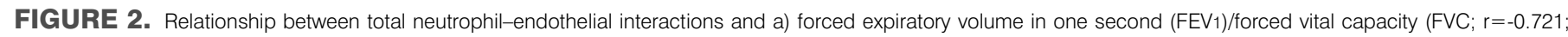
$p=0.012)$, and b) FEV $1 \%$ pred in chronic obstructive pulmonary disease patients with normal levels of $\alpha_{1}$-antitrypsin $(r=-0.273 ; p=0.416)$. Each point represents data from one subject.

when the data from the patient with the lowest FEV1/FVC was excluded from the analysis $(\mathrm{r}=-0.654 ; \mathrm{p}=0.04)$. No significant correlations were seen between lung function and neutrophil endothelial interactions in the other three groups.

\section{Neutrophil surface-adhesion molecule expression}

The expression of the adhesion molecules CD11a, CD11b, CD18, CD43, CD49d and CD62l on resting and fMLPstimulated neutrophils purified from the whole blood of the NS, HS, PiM and PiZ groups is shown in figure 3. KruskalWallis analysis revealed that the resting expression of CD11a differed significantly $(p<0.01)$ between the four groups, and paired analysis confirmed that this was due to significantly lower expression in the $\mathrm{PiZ}$ group $(\mathrm{p}<0.01)$. In addition, resting expression of CD62l was significantly different $(\mathrm{p}<0.05)$ between the four groups, and paired testing revealed that this was due to a significant difference between the PiM and PiZ groups (mean \pm SE $2.0 \pm 0.5$ versus $1.0 \pm 0.2, \mathrm{p}<0.05$ ).

On fMLP-stimulated neutrophils, the fluorescence intensity of $\mathrm{CD} 11 \mathrm{~b}$ and CD18, relative to unstimulated neutrophils, was significantly different between the four groups (Kruskal-Wallis $\mathrm{p}<0.05)$. Paired analysis revealed that this was due to a significantly greater upregulation of these two adhesion molecules in the PiM group compared with the PiZ group (mean \pm SE CD11b relative fluorescence intensity $1.4 \pm 0.1$ versus $1.1 \pm 0.1, \mathrm{p}<0.05$, in the PiZ group; CD18 relative fluorescence intensity $1.4 \pm 0.1$ versus $1.1 \pm 0.0, \mathrm{p}<0.05$, in the PiZ group). There were no differences between groups in any of the other adhesion molecules following neutrophil stimulation.

\section{DISCUSSION}

Neutrophil recruitment from the bloodstream into the airways is a complex process, involving a number of different adhesion molecules and inflammatory mediators, which cannot be interpreted easily by simple chemotaxis assays, such as the Boyden chamber. Furthermore, bloodflow through vessels subjects endothelial cells to shear stress, which can elicit cytoskeletal remodelling and activation of natural signalling cascades in endothelial cells, including the activation of
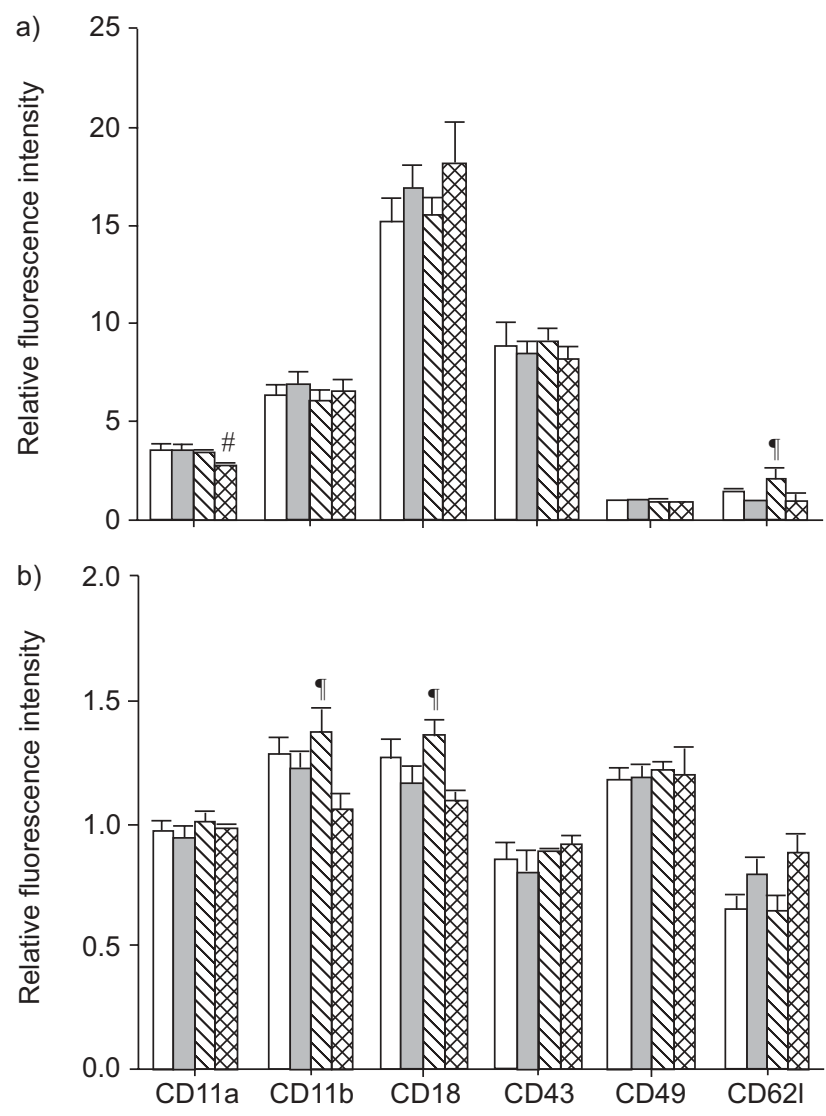

FIGURE 3. Adhesion molecule expression on a) resting and b) formylmethionyl-leucyl-phenylalanine-stimulated neutrophils from never-smokers (NS; $\square$ ), healthy smokers (HS; $\square$ ), chronic obstructive pulmonary disease (COPD) patients with normal $\alpha_{1}$-antitrypsin (AT) levels (PiM; $\mathbb{N}$ ) and COPD patients with $\alpha_{1}$-AT deficiency (PiZ; $)$. Data are presented as mean \pm SE fluorescence intensity relative to neutrophils treated with a nonspecific antibody (a) or relative to unstimulated neutrophils labelled with the same antibody (b). ${ }^{*}: \mathrm{p}<0.05$ versus NS, HS and PiM; •: $p<0.05$ versus PiZ. 
nuclear factor- $\kappa \mathrm{B}$ and upregulation of intracellular adhesion molecule (ICAM)-1 [15]. The flow-based assay used in the current study incorporates these aspects and, when used in conjunction with HUVEC, which have a similar adhesion molecule profile (following IL-1 $\beta$ stimulation) to that seen on bronchial post-capillary venules $[10,11]$, provides an appropriate model of neutrophil-endothelial cell interactions in the airways of patients with COPD.

Using this model, the current authors have demonstrated for the first time that the endothelial cell interactions and, in particular, the transendothelial migration of neutrophils purified from PiM smokers are significantly increased compared with NS, HS and PiZ patients. The PiZ group were younger, but otherwise the groups were well matched; in particular, the HS and COPD patients had a similar history of smoking. In addition, although significantly higher peripheral blood neutrophil counts in the PiM and PiZ groups were demonstrated, compared with NS, the neutrophil-endothelial interactions in the current study were corrected for the number of neutrophils infused, which suggests that the difference seen in neutrophil-endothelial cell interactions was independent of these factors.

A potential mechanism for the increased neutrophilendothelial cell interaction is an upregulation of neutrophil adhesion molecules. Mac-1 (CD11b/CD18) is thought to be critical in facilitating neutrophil adhesion via its endothelial counter receptor ICAM-1 [16]. Mac-1 is rapidly mobilised to the neutrophil surface following exposure to stimuli such as IL-8 [17], which is presented on the endothelial surface following cytokine stimulation [18]. In the current study, there was a small increase in the expression of CD62l (L-selectin) on resting neutrophils, and CD11b and CD18 (Mac-1) on fMLPstimulated neutrophils purified from the whole blood of the PiM patients; however, the differences only reached statistical significance when compared with the PiZ patients. The magnitude of this difference in Mac-1 upregulation and, hence, neutrophil-endothelial interaction is likely to be an underestimate of the true difference, given that the neutrophil purification process resulted in a degree of neutrophil activation, as has previously been demonstrated [14]. Given that COPD is a slowly progressive disease that develops over many years, even small increases in neutrophil-endothelial interactions are likely to produce a clinically significant increase in the neutrophil burden to the lungs of smokers over this time period.

Studies in COPD often suffer from the failure to recruit an appropriate control group. Although age-matched HS are generally included in such studies, interpretation of the results suffers from an inability to separate cause and effect. For this reason, one of the strengths of the current study is the inclusion of a matched group of patients with COPD related to an identified risk factor, namely $\alpha_{1}$-AT deficiency. COPD is thought to develop as a result of an imbalance between proteinases, such as neutrophil elastase, and proteinase inhibitors (predominantly $\alpha_{1}-\mathrm{AT}$ ), which can occur because of an excessive neutrophil load or deficiency of the relevant inhibitor. This overall mechanism is in keeping with the observation that neutrophils from patients with COPD due to severe $\alpha_{1}$-AT deficiency did not demonstrate increased endothelial interaction in the current study. In fact, although total neutrophil-endothelial interactions were similar in the PiZ, NS and HS groups, neutrophil transendothelial migration was significantly lower in the PiZ group compared with the other three groups. This was an unexpected finding, but may relate to the lower expression of CD11a on resting neutrophils, and CD11b and CD18 (Mac-1) on fMLP-stimulated neutrophils demonstrated in the $\mathrm{PiZ}$ patients, although this requires further study.

The development of airway inflammation, connective tissue damage and airflow obstruction in patients with severe $\alpha_{1}$-AT deficiency may occur despite normal/reduced neutrophilendothelial interactions because of an elastase- $\alpha_{1}$-AT imbalance related mainly to the inhibitor deficiency. Conversely, enhanced neutrophil-endothelial interactions may contribute to the development of COPD in smokers with normal $\alpha_{1}$-AT levels by increasing neutrophil recruitment to the lungs, resulting in greater elastase burden and collateral lung damage, even in the presence of normal $\alpha_{1}$-AT. Further supporting evidence for this hypothesis is the inverse correlation seen between neutrophil-endothelial cell interactions and the FEV1/FVC ratio in the PiM patients, but not those with $\alpha_{1}$-AT deficiency, suggesting an association between enhanced neutrophil-endothelial interactions in PiM subjects and the presence of COPD.

In summary, the data show that peripheral blood neutrophils from smokers with normal levels of $\alpha_{1}$-antitrypsin who have developed chronic obstructive pulmonary disease demonstrate enhanced endothelial interaction under flow, compared with smokers who have not developed the disease. Furthermore, neutrophil-endothelial interaction was not increased in chronic obstructive pulmonary disease patients with $\alpha_{1}$-antitrypsin deficiency, suggesting that this is not simply an effect of the disease itself, but may be a predisposing factor in smokers without the deficiency. Further work is required to clarify the mechanism, but upregulation of the adhesion molecule macrophage antigen-1 may be responsible. The neutrophil priming demonstrated in the current study may provide a new therapeutic target for patients with chronic obstructive pulmonary disease and normal levels of $\alpha_{1}$-antitrypsin.

\section{REFERENCES}

1 Saetta M, Turato G, Maestrelli P, Mapp CE, Fabbri LM. Cellular and structural bases of chronic obstructive pulmonary disease. Am J Respir Crit Care Med 2001; 163: 1304-1309.

2 Stockley RA. Neutrophils and the pathogenesis of COPD. Chest 2002; 121: Suppl. 5, 151S-155S.

3 Doerschuk CM. Leukocyte trafficking in alveoli and airway passages. Respir Res 2000; 1: 136-140.

4 Ibbotson GC, Doig C, Kaur J, et al. Functional alpha4integrin: a newly identified pathway of neutrophil recruitment in critically ill septic patients. Nat Med 2001; 7: 465-470.

5 Seveau S, Keller H, Maxfield FR, Piller F, HalbwachsMecarelli L. Neutrophil polarity and locomotion are associated with surface redistribution of leukosialin (CD43), an antiadhesive membrane molecule. Blood 2000; 95: 2462-2470. 
6 Noguera A, Batle S, Miralles C, et al. Enhanced neutrophil response in chronic obstructive pulmonary disease. Thorax 2001; 56: 432-437.

7 Burnett D, Chamba A, Hill SL, Stockley RA. Neutrophils from subjects with chronic obstructive lung disease show enhanced chemotaxis and extracellular proteolysis. Lancet 1987; 2: 1043-1046.

8 Pauwels RA, Buist AS, Ma P, Jenkins CR, Hurd SS, GOLD Scientific Committee. Global strategy for the diagnosis, management, and prevention of chronic obstructive pulmonary disease: National Heart, Lung, and Blood Institute and World Health Organization Global Initiative for Chronic Obstructive Lung Disease (GOLD): executive summary. Respir Care 2001; 46: 798-825.

9 Jaffe EA, Nachman RL, Becker CG, Minick CR. Culture of human endothelial cells derived from umbilical veins. Identification by morphologic and immunologic criteria. J Clin Invest 1973; 52: 2745-2756.

10 Scholz D, Devaux B, Hirche A, et al. Expression of adhesion molecules is specific and time-dependent in cytokinestimulated endothelial cells in culture. Cell Tissue Res 1996; 284: 415-423.

11 Gonzalez S, Hards J, Van Eeden S, Hogg JC. The expression of adhesion molecules in cigarette smoke-induced airways obstruction. Eur Respir J 1996; 9: 1995-2001.
12 Cooke BM, Usami S, Perry I, Nash GB. A simplified method for culture of endothelial cells and analysis of adhesion of blood cells under conditions of flow. Microvasc Res 1993; 45: 33-45.

13 Jones DA, Smith CW, McIntre L. Effects of fluid shear stress on leucocyte adhesion to endothelial cells. In: Granger DN, Schmid-Schonbein GW, eds. Physiology and pathophysiology of leukocyte adhesion. New York, Oxford Universtiy Press, 1995; pp. 148-168.

14 Bateman J, Parida SK, Nash GB. Neutrophil integrin assay for clinical studies. Cell Biochem Funct 1993; 11: 8791.

15 Ballermann BJ, Dardik A, Eng E, Liu A. Shear stress and the endothelium. Kidney Int Suppl 1998; 67: S100S108.

16 Diamond MS, Staunton DE, de Fougerolles AR, et al. ICAM-1 (CD54): a counter-receptor for Mac-1 (CD11b/ CD18). J Cell Biol 1990; 111: 3129-3139.

17 Huber AR, Kunkel SL, Todd RF 3rd, Weiss SJ. Regulation of transendothelial neutrophil migration by endogenous interleukin-8. Science 1991; 254: 99102.

18 Tanaka Y, Adams DH, Shaw S. Proteoglycans on endothelial cells present adhesion-inducing cytokines to leukocytes. Immunol Today 1993; 14: 111-115. 